\title{
FATORES DE (DES)MOBILIZAÇÃO SOCIAL NO ENFRENTAMENTO À PANDEMIA DE COVID-19 PELAS POPULAÇÕES PERIFÉRICAS DE BELO HORIZONTE, MINAS GERAIS
}

\author{
Laura Nayara Pimenta ${ }^{1}$ \\ Márcio Simeone Henriques ${ }^{2}$ \\ Marlene Pereira Machado ${ }^{3}$
}

Resumo:

A emergência da pandemia de Covid 19 acarreta profundas mudanças no cotidiano. No Brasil, uma das questões é como e em que condições essa situação atinge públicos mais vulneráveis. Aqui nos referimos sobretudo às populações periféricas, que padecem com várias mazelas que as colocam à mercê da fome e da doença. Iniciativas comunitárias têm surgido para mitigar essa conjuntura, mas elas demandam solidariedade e empatia dos sujeitos, o que nem sempre acontece. Através de um olhar comunicacional sobre as dinâmicas de (des)mobilização, aqui buscamos compreendê-las a partir de três vertentes: condições de contato; condições de coletivização e condições de empatia. Tomamos para análise o $1^{\circ}$ Encontro do Periferia Viva - Força-Tarefa Covid 19, um projeto articulador realizado em Belo Horizonte.

Palavras-chave: Mobilização Social; Públicos; Periferia; Covid 19.

\begin{abstract}
:
The emergence of the Covid pandemic 19 brings profound changes in daily life. In Brazil, one of the questions is how and under what conditions this situation affects the most vulnerable publics. Here we are referring mainly to peripheral populations, who suffer from various ailments that place them at the mercy of hunger and disease. Community initiatives have appeared to mitigate this situation, but they demand solidarity and empathy from the subjects, which is not always the case. Through a communicational look at the dynamics of (de)mobilization, here we seek to understand them from three aspects: contact conditions; conditions of collectivization and conditions of empathy. We took for analysis the $1^{\circ}$ Meeting of Periferia Viva - Task Force Covid 19, an articulating project carried out in Belo Horizonte.
\end{abstract}

Keywords: Social Mobilization; Publics; Periphery; Covid 19.

\footnotetext{
1 É doutora em Comunicação e Sociabilidade pelo Programa de Pós-graduação em Comunicação da Universidade Federal de Minas Gerais e mestra pela mesma instituição. Foi bolsista de doutorado sanduíche na Faculdade de Ciências da Comunicação da Universidade Nacional de Córdoba, Argentina. É pesquisadora do Grupo de Pesquisa em Comunicação, Mobilização Social e Opinião Pública - Mobiliza, coordenado pelo Professor Dr. Márcio Simeone Henriques.

2 Professor do Departamento de Comunicação Social e do Programa de Pós-Graduação em Comunicação Social da UFMG. Coordenador do Grupo de Pesquisa em Comunicação, Mobilização Social e Opinião Pública - Mobiliza. Doutor em Comunicação pela UFMG, com Pós-Doutorado na Universidade Nova de Lisboa - Portugal.

${ }^{3}$ Doutoranda em Comunicação na Universidade Federal de Minas Gerais (UFMG - Bolsista Capes/Proex), Mestre em Comunicação pelo Programa de Pós-graduação em Comunicação Social - Interações Midiáticas da PUCMinas, MBA em Gestão pela Fundação Dom Cabral, pós-graduação em Comunicação e Gestão Empresarial pela PUC-Minas, Jornalista e membro dos grupos de pesquisa Comunicação no contexto organizacional: aspectos teórico-conceituais - DIALORG (PUC-Minas/CNPQ) e Comunicação, Mobilização Social e Opinião Pública MOBILIZA (UFMG). E-mail: marlenemachadobh@hotmail.com. ORCID: https://orcid.org/0000-0001-6028-5907
} 
Introdução

A emergência da pandemia de Covid 19, pela sua magnitude e poder de afetação, acarreta profundas transformações no cotidiano. Dentre inumeráveis efeitos, em cada país, ou em cada território, além do que há de comum na progressão da doença, efeitos bem singulares são socialmente produzidos, dependendo de variadas condicionantes, onde as formas de reação, de apropriação, de enfrentamento se produzem. No Brasil, uma das questões é como e em que condições essa situação atinge públicos mais vulneráveis, escancarando e ampliando suas debilidades. Assim, as grandes assimetrias e desigualdades, grandes divisões sociais, traços estruturais do país, ao se acentuarem, revelam ainda com maior ímpeto as condições de pobreza, de subcidadania, de preconceitos e as situações de violações de direitos de vasta parcela da população. Aqui nos referimos especialmente às populações das periferias, termo que pode ter sentido menos ou mais amplo, mas que serve para designar todo um contingente populacional cuja fragilidade possa ser reconhecida justamente nas desigualdades sociais. Desde o início da pandemia no país, que notoriamente atingiu de pronto parcelas da população dos estratos mais altos, percebeu-se também que, pelas características epidemiológicas e pelos fatores sócio-econômicos, a doença não tardaria a se espalhar pelos estratos mais pobres, com menores chances de uma prevenção eficaz e acessos mais difíceis aos tratamentos, tudo isso em meio ao problema imediato da fome e da falta de recursos básicos de saneamento e higiene. Por serem áreas de alta densidade populacional, em que a maior parte das moradias aglomera muitas pessoas no mesmo espaço, e apresentarem baixo acesso a serviços básicos de saúde, educação e alimentação, as periferias das grandes cidades estão muito expostas à contaminação, a complicações e a riscos gerados pela infecção de Covid 19.

Desde então, várias iniciativas se organizaram para mitigar estes impactos e melhorar as condições de enfrentamento e as próprias periferias acionaram seus canais comunitários para encarar o desafio, por conta própria ou em alianças e parcerias: associações de moradores, organizações não-governamentais, coletivos, grupos de cultura, dentre outros, redirecionaram suas ações, emergencialmente, para atender às famílias que já começavam a passar fome, realizando ações de cadastro, arrecadação e distribuição de cestas básicas e de material de higiene, criando financiamentos coletivos online etc. Além disso, novas iniciativas surgiram para lidar especificamente com as consequências da pandemia, também atuando na área de segurança alimentar e promoção/proteção da saúde. 
Mesmo diante de toda essa mobilização e articulação comunitária, observamos que esses grupos e coletivos dependem de uma sensibilização de sujeitos que não são das periferias, daquelas pessoas e instituições que têm condições de doar ou contribuir de alguma forma e as que transitam entre centro e periferia. Precisam falar para além delas mesmas, atingir outros públicos, almejando uma corresponsabilidade destes. E são inúmeros os exemplos de solidariedade neste sentido. Porém, numa visão para além das ações imediatas de mitigação e de enfrentamento, em que condições se poderia obter um envolvimento e uma movimentação mais amplos para dar conta de uma situação tão complexa onde os mais variados problemas se emaranham?

Para tanto, adotamos uma abordagem na perspectiva da comunicação nos processos de mobilização social, cujo foco está nos processos comunicativos implicados na formação e movimentação dos públicos. Uma aposta dessa vertente é o olhar microscópico sobre o tema, propício para conferir centralidade às dimensões da visibilidade, disponibilidade e generalidade que configuram as condições de um público expressar-se (HENRIQUES, 2010, 2017) e abrem-se para uma dimensão coletiva mais ampla de opiniões e atitudes.

A emergência de uma pandemia como a da Covid-19 é bastante desafiadora, sob vários aspectos. Ela chama ao enfrentamento da situação nos níveis individual e coletivo, tanto quanto cria obstáculos à ação, impondo distanciamentos. Algo que interfere tão severamente no cotidiano, desafia as próprias condições de vida e de sociabilidade das pessoas e tem um poder de afetação direta e indireta sobre os sujeitos, desperta divergências, controvérsias, opiniões e atitudes por vezes contraditórias; forma e movimenta públicos numa grande intensidade e velocidade. É atravessada por múltiplos fatores sociais, políticos, culturais, econômicos, científico-sanitários, de modo tão intenso que gera dúvidas, medos, desconfianças. Como um par dialético da mobilização, a ideia de desmobilização pode ser pensada a partir dessas mesmas dimensões, dinâmicas e fatores.

Olhar para alguns dos fatores que dificultam a mobilização é importante para entendermos os aspectos que obstruem que determinadas questões transcendam a preocupação de grupos específicos e alcancem a atenção pública, inibem o envolvimento de outros públicos e os levam a uma ação menos efetiva, mas também para compreendermos como são as estratégias e táticas empregadas para vencer esses obstáculos. No atual contexto de pandemia, esses fatores emergem de muitas formas, revelando muitas nuances sobre as condições de empatia e solidariedade entre os sujeitos, sobre as dificuldades de se alcançar uma corresponsabilidade dos públicos em causas coletivas postas em cena pela pandemia. Não tratam essas causas apenas do 
enfrentamento imediato à epidemia e suas consequências diretas, mas de uma miríade de problemas que tal situação traz à tona, em todos os campos. No contexto brasileiro, este cenário emergente evidencia fortemente as assimetrias e desigualdades sociais e econômicas, formando e movimentando públicos com divisões bem demarcadas. Podemos observar essas questões em iniciativas que têm se organizado nas periferias das grandes cidades para enfrentar as consequências trazidas pela pandemia.

Colocamos aqui em análise o caso do Projeto Periferia Viva - Força-tarefa Covid-19 (PV), criada pela Agência de Iniciativas Cidadãs (AIC) ${ }^{4}$, em aliança com o Fórum das Juventudes da Grande BH, a Laço - Associação de Apoio Social e a Universidade Federal de Minas Gerais (UFMG). Trata-se de uma iniciativa que é basicamente de comunicação, ou seja, com o propósito de promover aproximações, fazer circular as informações e gerar vínculos entre públicos que, de outra forma, poderiam não ocorrer. Com atuação prioritária na Região Metropolitana de Belo Horizonte, Minas Gerais, a força-tarefa foi criada para dar visibilidade e articular apoios e parcerias aos esforços já em curso de mobilização social e vigilância civil para o enfrentamento à pandemia do coronavírus na perspectiva da defesa do direito à vida, à dignidade e à cidadania das populações periféricas.

Tomando com base essa atuação, no presente texto desenvolvemos um raciocínio pautado na perspectiva da ação dos públicos para evidenciar esses fatores de (des)mobilização. Alguns aspectos chamaram a nossa atenção, especialmente após a realização do $1 .^{\circ}$ Encontro do Periferia Viva. De um lado, uma intensa mobilização de grupos, coletivos, entidades diversas, com diferentes tipos de atuação, demonstrando enorme vitalidade e proporcionando várias articulações. De outro lado, uma série de dificuldades, de obstáculos, muitas queixas quanto às próprias condições de mobilização. Daí porque trataremos de focalizar especialmente essas barreiras comunicacionais que são percebidas por estes públicos. Desse modo, na primeira seção traçamos um panorama da abordagem comunicacional sobre os públicos e suas movimentações, a partir de três vertentes: as condições de contato, as condições de coletivização e as condições de empatia. Na segunda parte fazemos o estudo e análise do caso, onde iniciamos por situar o cenário da pandemia de Covid-19 nas periferias de Belo Horizonte. Em seguida, exploramos os fatores que inibem a mobilização, na visão dos públicos mobilizados, olhando

\footnotetext{
${ }^{4}$ A AIC - Agência de Iniciativas Cidadãs chamava-se Associação Imagem Comunitária até outubro de 2020, quando alterou sua razão social. É uma entidade parceira do Departamento de Comunicação Social da Universidade Federal de Minas Gerais em projetos de ensino, pesquisa e extensão.
} 
especificamente para os materiais gerados no Encontro: sua gravação, as sistematizações das discussões grupais e seu relatório final, que nos dão um panorama sobre as iniciativas articuladas pelo projeto e a situação das periferias e compõem nosso corpus de exploração.

\section{Um olhar para a (des)mobilização social}

Mencionamos aqui a (des)mobilização de um modo provocativo, a partir de um olhar que apreenda a formação e movimentação de públicos. Henriques (2010, 2012, 2017) sugere que o entendimento das lógicas comunicativas que regem tais grupos está vinculado a uma exploração das formas de ação coletiva dos públicos. Incorporando a dimensão da ação como constitutiva dessas formas coletivas, na esteira da perspectiva trabalhada por Dewey (1954), Henriques (2017, p. 54) pensa os públicos como “formas abstratas e dinâmicas de experiência e de sociabilidades que se formam em função da problematização de acontecimentos e ações que afetam os sujeitos”. Em sua visão, os públicos existem em referência tanto a outros públicos quanto às instituições.

Nessa perspectiva, o processo mobilizador está sempre sob a tensão de forças multidirecionais, que ora viabilizam o engajamento a uma causa, ora o obstruem, por isso é apropriado falarmos de dinâmicas de mobilização/desmobilização. Esta referência se faz apenas no sentido de evidenciar uma tensão entre campos de força opostos que formam as condições em que um processo mobilizador se dá. No caso deste texto, nos interessa explorar e compreender as forças que inibem a mobilização, realçar como a ausência ou déficit de algumas condições geram uma força contrária aos esforços de mobilização ${ }^{5}$. 0 caso estudado nos permitiu observar alguns fatores, que aqui abordaremos em três vertentes: a primeira tem a ver com as condições de contato, ou seja, com a configuração do vínculo na presença, algo que é desafiado pela necessidade de isolamento e distanciamento social instaurado pela pandemia; a segunda tem a ver com as condições de problematização e coletivização do próprio enfrentamento à pandemia, onde entram em jogo a negação e os silenciamentos - os constrangimentos como insegurança, incerteza, medo, dúvida etc; a terceira tem a ver com a empatia, tendo em conta que sua ausência

\footnotetext{
5 Ao tratarmos de (des)mobilização, com tal grafia, estamos tratando, portanto, da própria mobilização, apenas enfatizando uma tensão e uma oposição constitutivas desse processo, que se dá na comunicação e, ainda, os aspectos de ação estratégica dos públicos mobilizados no sentido de criar as melhores condições e de superar os fatores que prejudicam sua ação e movimentação em público.
} 
ou deficiência configuram um obstáculo ao estabelecimento de relações de solidariedade mais sólidas e, consequentemente, da formação de uma corresponsabilidade.

a) Condições de contato - Nesta vertente, consideramos a radical mudança nas maneiras pelas quais os indivíduos se organizam por meio das interações. Ou seja, houve uma alteração nos regimes de sociabilidade dos sujeitos ocasionada pelas medidas de isolamento e distanciamento instauradas pela pandemia de Covid-19. Nas periferias, há uma tendência de os contatos serem mais próximos e marcados pela presença. A necessidade de isolamento rompe com esse contato presencial, traz dificuldades logísticas e também comunicacionais, demandando um uso intenso das mídias digitais para se manterem as articulações, ao passo que a infraestrutura necessária para tal permanece precária. O distanciamento também cria obstáculos à ação, interfere severamente no cotidiano e na movimentação dos públicos.

Toro e Werneck (2004) ressaltam que a mobilização social é um ato de comunicação por si, um processo de partilha de discursos, visões e informações, construindo uma ordem de convivência e que a estabilidade e sucesso neste processo depende de as pessoas saberem que o mesmo que fazem e decidem está sendo feito e decidido também por outros, em seus respectivos campos de atuação. Henriques et al. (2013) também valorizam o encontro e a reunião dos sujeitos como a base para o compartilhamento de sentimentos, conhecimentos e responsabilidades, o que se dá tanto em espaços físicos quanto virtuais, no âmbito privado e no âmbito público.

b) Condições de problematização e coletivização - A coletivização é o processo de constituição da causa social que anima um público, para o qual existem condições lógicas que entram em jogo nessa formação, como a concretude e percepção de uma causa/situação problemática, seu caráter público, a viabilidade de solucioná-la e o acionamento de sentidos mais amplos que permitam seu ancoramento na realidade (HENRIQUES, 2010, 2012). Esse processo de geração de uma causa é interativo, aberto, complexo e mantém com o processo mobilizador uma relação reflexiva, ou seja, a mobilização ocorre em função de uma causa, ao passo que a própria afirmação pública da causa depende da movimentação dos públicos ao seu redor. Henriques (2012) destaca que essa movimentação em prol de uma causa ocorre no confronto e no esforço gasto em compartilhar e gerar algo em comum.

Todavia, há processos que interferem nessas condições como, por exemplo, quando os sujeitos concordam tacitamente em ignorar algo de que eles estão cientes e sabem que é problemático, quando existem constrangimentos, embaraços, negação social e até 
mesmo tabus que levam os sujeitos a um silêncio social. Em suas pesquisas, Pimenta (2019) traz a perspectiva de Zerubavel para dizer dessas dinâmicas de silenciamento e desatenção, tratando dos fatores que obstruem a mobilização social. Ao contrário do que se possa imaginar, esse silêncio não gira em torno de questões imperceptíveis, mas envolve assuntos altamente visíveis que os sujeitos deliberadamente tentam evitar, como é, historicamente, o caso da situação das periferias. É importante enfatizar que a separação daquilo que é notado do que é ignorado é longe de ser natural. Zerubavel $(2006,2015)$ aponta que tal separação é, na verdade, o resultado de pressões, o produto de normas sociais de atenção destinadas a separar o que convencionalmente se considera notável do que se considera mero ruído de fundo. Desse modo, perceber e ignorar são ações realizadas por membros de comunidades. Estas fazem mais do que simplesmente oferecer aos seus membros sugestões sobre o que eles podem achar digno de atenção. Elas também orientam sobre quando devem fingir desatenção, ainda que sejam incapazes de fazê-lo.

Para além do ato de ignorar, negar e não dar atenção, Silva (2019) argumenta que, enquanto par dialético da mobilização, é frutífero pensar que a desmobilização ocorra a partir de um processo inverso ao da coletivização, que tenta demonstrar que um problema não é concreto, não é de interesse público, não é passível de solução e não é embasado em valores mais amplos. Adverte, ainda, que não se trata apenas de fazer com que um sujeito não entenda uma situação como problemática, mas sim de construir apelos capazes de desmotivá-lo, demonstrando que um problema não é passível de solução, ou mesmo pela desmoralização de sujeitos, grupos ou instituições que apontam e denunciam tal situação.

A pandemia é atravessada por múltiplos fatores sociais, políticos, culturais, econômicos, científico-sanitários, de modo tão intenso que gera dúvidas, medos, desconfianças. Além disso, é notória a presença de aspectos de negação da existência da doença e sua propagação, um questionamento de sua concretude. No caso das periferias, as diversas inseguranças sociais - alimentar, sanitária, física, econômica - também impactam na movimentação dos públicos.

c) Condições de empatia - Para além das vertentes supracitadas, que podem ocorrer simultaneamente, outro ponto diz sobre a dificuldade de se estabelecerem relações empáticas e solidárias, com vistas a alcançar a corresponsabilidade dos sujeitos. Sobre a empatia, Krznaric (2015) a entende como uma força de mudança social, um esforço consciente em que os sujeitos se colocam no lugar de outros, compreendendo seus sentimentos e perspectivas, utilizando essa compreensão para guiar suas próprias ações. Tal postura demanda uma escuta radical e precisa se constituir como uma força coletiva 
que pode alterar os contornos da paisagem social e política. Interessa-nos especialmente a sua posição de que um déficit de empatia é algo marcado por uma introspecção que dificulta que os sujeitos se engajem em causas que não os envolvam diretamente. A falta de empatia com as populações vulneráveis, periféricas, parece dificultar a interação entre a periferia e a não periferia, amplia o fosso que separa a periferia do centro, fortalecendo a aparição deste fator de desmobilização.

Com base no exposto, podemos perceber que diversos fatores incidem sobre o potencial dos sujeitos sentirem-se corresponsáveis, desenvolverem uma empatia por outrem e agirem para a mudança de determinada realidade. Outros aspectos também interferem nesse processo e, neste texto, nosso objetivo é olhar para o que obstrui a formação e movimentação de públicos ao redor das iniciativas de mitigação dos impactos da pandemia de Covid-19 nas comunidades periféricas e para algumas pistas de como os atores mobilizados procuram vencer esses obstáculos.

Apesar de o Periferia Viva ser uma ação de articulação comunitária com vistas a gerar engajamentos para mitigar as consequências da pandemia nas periferias de $\mathrm{BH}$, sua execução nos revela elementos importantes que indicam as diversas forças que tensionam o processo mobilizador, do ponto de vista comunicacional. A atuação "na" e "com" a periferia em tempos de pandemia escancara as desigualdades sociais, mostra o déficit de acesso à internet e outras tecnologias da comunicação, evidencia uma faceta importante do isolamento social: a mudança nas formas de sociabilidade. Ademais, este caso, visto pelas discussões estabelecidas no primeiro encontro virtual com as iniciativas, nos permite ver os atores periféricos em ação e o que eles enunciam e declaram como desafios às suas ações de mobilização.

\section{Covid-19 nas quebradas de BH: fatores de (des)mobilização}

Marcadas por unidades habitacionais carentes de serviços públicos essenciais e que tenham ocupado terreno de propriedade alheia (privada ou pública), estando dispostas, em geral, de forma desordenada e densa, as vilas e favelas representam 11,45\% dos domicílios de Belo Horizonte, totalizando um percentual de $15 \%$ da população do município (IBGE, 2020). Estamos falando de mais de 400 mil pessoas vivendo em situação precária e de grande adensamento. Neste esteio, pensar a periferia no contexto da pandemia nos leva à 
necessidade de refletir sobre uma rotina muito singular, para além dos padrões convencionais de prevenção a qualquer doença.

Nos dados apresentados nos boletins epidemiológicos da Prefeitura de Belo Horizonte não há informações específicas sobre a incidência da Covid-19 nas periferias. Essa ausência foi suprida pelo Observatório de Saúde Urbana de BH (OSUBH), que publicou estudos sobre o avanço da pandemia nas vilas e favelas da cidade. O estudo da OSUBH (2020) revela que após o vírus se espalhar por toda a cidade, ele se concentra em territórios onde há condições mais rápidas de transmissão e adoecimento, não apenas relacionadas a características individuais, como obesidade, hipertensão e diabetes, mas, principalmente, às condições socioeconômicas desfavoráveis. Na Figura 1 podemos ver a incidência de óbitos pela doença nas zonas das vilas e favelas de $\mathrm{BH}^{6}$.

${ }^{6}$ Dados referentes a julho de 2020 , quando foi realizado este trabalho. 
Figura 1. Densidade de localização de residência dos óbitos

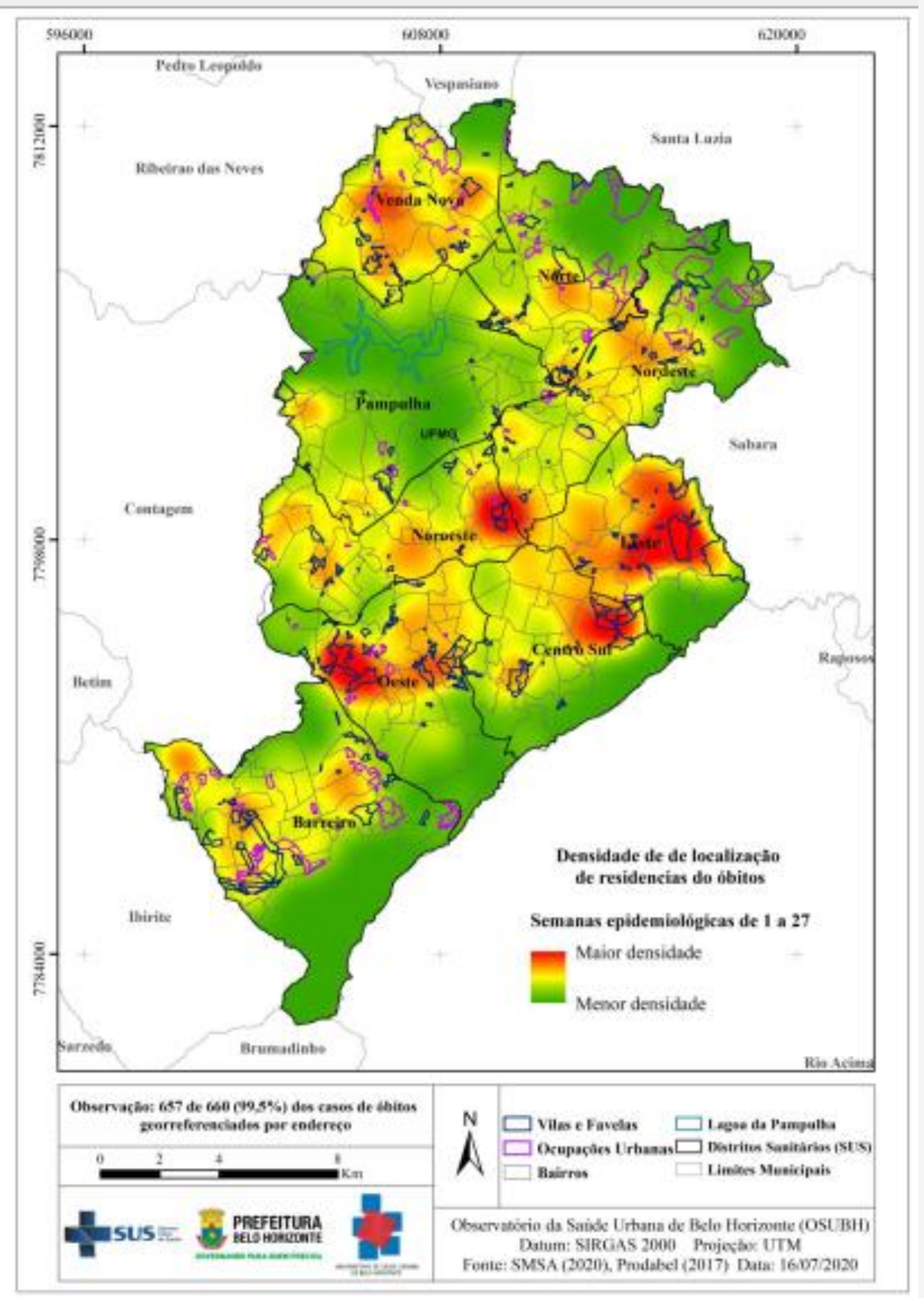

Fonte: $4^{\circ}$ InfoCovid (OSUBH, 2020).

Podemos observar até então uma grande ocorrência de óbitos nas vilas e favelas pela Covid-19, somando-se a todo um contexto de mazelas relacionadas às questões 
socioeconômicas precárias. É nesse cenário complexo que inúmeras iniciativas, internas e externas às periferias, têm incidido, seja para garantir a segurança alimentar das famílias, seja para levar informações confiáveis ou para promover/proteger a saúde destas. A forçatarefa Periferia Viva, atuante em BH e Região Metropolitana, tem um importante papel articulador dessas iniciativas. O projeto consiste numa plataforma que congrega um conjunto de ações para conectar, neste contexto de pandemia, quem precisa de ajuda com quem pode ajudar. Fora os profissionais das instituições realizadoras - AIC, Fórum das Juventudes, Laço e UFMG - mais de 30 voluntários colaboram nas quatro frentes de atuação do projeto - escuta e articulação social, assessoria de comunicação às iniciativas, produção de conteúdo sobre elas e articulação de parcerias. Nos primeiros quatro meses de pandemia, o PV distribuiu mais de mil cestas básicas, 600 litros de leite e 500 quilos de tecidos, para produção de máscaras, além de ter realizado o cadastro de mais de 90 iniciativas.

O trabalho desenvolvido pelo projeto foi concebido e colocado em ação por atores externos às periferias, mas que têm grande poder de mediar as relações e almejam criar uma rede de apoio mútuo. Ele revela a necessidade da atuação de um agente externo para sensibilizar mais pessoas para além da população periférica e desvela a dificuldade que tal população tem em sensibilizar outros públicos. 0 trabalho de escuta social do projeto fez emergir uma série de elementos que torna a situação das periferias nevrálgica, seja pela drástica mudança nas formas comuns de sociabilidade, seja pelo baixo acesso à internet e outras tecnologias da comunicação, dentre outros fatores. Foi justamente para entendermos melhor esses fatores que inibem a mobilização que estabelecemos um recorte nas iniciativas cadastradas na plataforma Periferia Viva, o que nos permite um olhar panorâmico sobre a situação das periferias de BH e sua Região Metropolitana

Mas, como olhar para mais de 90 iniciativas sociais e seus propósitos? Aproveitamos a oportunidade da realização do $1 .^{\circ}$ Encontro do Periferia Viva, ocorrido em 14 de julho de 2020, por meio da plataforma digital Zoom, que reuniu mais de 50 pessoas, dentre lideranças comunitárias das iniciativas cadastradas e parte da equipe do projeto. Durante o encontro, os participantes foram divididos em nove grupos mediados, nos quais discutiram sobre os desafios, os aprendizados, as tendências de mudança no trabalho comunitário e a percepção de atuação em rede.

Cada grupo gerou uma síntese das discussões na plataforma Jamboard. Também usamos como referência a gravação na íntegra do encontro e o relatório final produzido também pela equipe do Periferia Viva. Isso nos permitiu tratar de forma prospectiva dos 
fatores comunicacionais que incidem sobre as condições e as dinâmicas de (des)mobilização.

No contexto da pandemia, em sua incidência sobre as populações periféricas, as discussões revelam que predomina um sentimento de insegurança multifacetado nessas populações, não só a insegurança alimentar, mas também a insegurança física, relacionada às condições sanitárias inadequadas e às diversas violências acirradas; a insegurança social, caracterizada pelo desamparo estatal, o desemprego e a crise política; além da insegurança ligada às incertezas sobre o futuro diante desse cenário pandêmico. Outro elemento que emerge é a multiplicidade de demandas. As famílias não demandam apenas alimentos e materiais de higiene, mas atendimento médico, remédios, materiais de construção, roupas, uma infinidade de itens e serviços, como se as iniciativas solidárias fossem capazes de suprir integralmente o papel do Estado.

No que se refere aos fatores comunicacionais, que são de nosso maior interesse, com vistas a uma análise mais qualificada, consideramos três vertentes: (a) condições de contato, (b) condições de problematização e coletivização e (c) condições de empatia. Elementos que corroboram essas vertentes aparecem fortemente nas falas dos participantes do $1 .^{\circ}$ Encontro, com grande incidência nas interações, estabelecendo uma certa incomunicação que reverbera por entre esses públicos. Para melhor compreensão desses fatores, detalharemos cada vertente separadamente, evidenciando esses elementos na análise discursiva de alguns proferimentos extraídos dos grupos de discussão do encontro.

a) Condições de contato - Buscando compreender como as condições de contato interferem no processo mobilizador em prol das causas das periferias, extraímos alguns proferimentos que dizem dessas condições, conforme elencado no Quadro 1.

Quadro 1. Proferimentos sobre as condições de contato

\section{Proferimentos sobre as condições de contato}

“Dificuldade de acesso a comunicação (sobre a prevenção, cesta básica ou auxílio emergencial). Grande maioria do grupo são mulheres idosas, que têm dificuldade de aprender tecnologia e às vezes também nem gostam de usar". (Participante do Grupo 2) 
“Apesar de o cenário devastador, percebemos um contexto de muita solidariedade e troca”. (Participante do Grupo 3).

“A ausência física do Estado fez e está fazendo muito falta durante a pandemia. Os CRAS e CREAS eram a referência da comunidade para muitos assuntos. Durante a pandemia, estão fechados, não há telefones que possamos nos instruir, não se sabe onde está a informação. As lideranças comunitárias muitas vezes têm que buscar informações que não estão disponíveis para a população". (Participante do Grupo $4)$.

“...o analfabetismo digital e a falta de acesso a equipamentos tecnológicos dificultam não só o acesso à informação mas também as mobilizações na periferia”. (Participante do Grupo 7)

Fonte: Elaborado pelos autores.

Esses proferimentos revelam que, no que tange às condições de contato, o isolamento, as barreiras físicas, tecnológicas, de logística e de mobilidade tornaram-se mais intensas. As linhas de comunicação estão mais escassas, as pessoas têm menos disponibilidade para o encontro presencial, até mesmo por conta da necessidade de distanciamento social. E as condições para se comunicar, para mover-se no espaço público, com uma boa parte da população confinada e outra parte sem ter como confinar, agora são diferentes. São condições de sociabilidade que foram profundamente alteradas.

Dessa maneira, os participantes manifestam suas preocupações sobre como fazer para que a comunicação flua. O domínio da tecnologia e suas funcionalidades é uma imposição para amenizar esse isolamento, segundo os líderes comunitários. A exclusão digital, como registram, funciona como uma barreira à atuação na periferia. A logística na entrega das doações é outro dificultador apontado pela exclusão digital, assim como o acesso às pessoas beneficiadas, que não têm telefone, internet ou whatsapp. "Como aumentar a presença digital e usar as ferramentas digitais?”, indaga um participante do Grupo 1.

É por meio da tecnologia que se acionam as redes para buscar doações, que se organizam as demandas da comunidade. É por meio da tecnologia que se consegue ajudar comunidades invisíveis, que sequer têm cadastros e documentos para participar dos 
programas governamentais. Dessa maneira, manter as doações, dar segurança e apoio à comunidade passam a ser necessidades emergenciais.

As demandas para uma comunicação ágil e clara são urgentes na periferia. Ela é o meio para manter as pessoas assistidas informadas sobre as doações, sobre seus direitos e para mantê-las mobilizadas, num contexto em que a comunidade já têm que lidar com o fechamento dos equipamentos públicos e a ausência do Estado. É um grande desafio conter os fatores que comprometem a mobilização. Falta conhecimento sobre os locais onde as pessoas moram e faltam também equipamentos de segurança, para ter contato mais seguro com elas. Até mesmo o conhecimento aprofundado sobre os conceitos de vulnerabilidades são necessidades apontadas pelos voluntários para agir na pandemia.

b) Condições de Problematização e Coletivização - Sobre as condições de coletivização, extraímos alguns proferimentos, conforme elencados no Quadro 2.

\section{Quadro 2. Proferimentos sobre as condições de coletivização}

\begin{tabular}{|c|}
\hline Condições de Coletivização - Proferimentos ressaltados \\
\hline $\begin{array}{l}\text { “Começar sem saber por onde. Sabia que era preciso algo, mas não sabia o quê, } \\
\text { não entendia bem o que era a doença." (Participante do Grupo 2) }\end{array}$ \\
\hline $\begin{array}{l}\text { “Daqui para frente ainda há muitas incertezas. Precisamos fortalecer os vínculos } \\
\text { que tecemos durante a pandemia e estabelecer novas conexões”. (Participante do } \\
\text { Grupo 2) }\end{array}$ \\
\hline $\begin{array}{l}\text { "Risco de estar contaminado assintomático e espalhar entre as pessoas que estão } \\
\text { sendo ajudadas." (Participante do Grupo } 2 \text { ) }\end{array}$ \\
\hline $\begin{array}{l}\text { “Ter um cadastro único que possa direcionar as doações, garantindo que todos } \\
\text { recebam, sem duplicidade. Atender a pessoa certa, no momento certo, com a coisa } \\
\text { certa.” (Participante do Grupo 4) }\end{array}$ \\
\hline $\begin{array}{l}\text { "Como cobrar a presença do Estado? Fazer com que as pessoas entendam seus } \\
\text { direitos e lutem por eles." (Participante do Grupo 4). }\end{array}$ \\
\hline
\end{tabular}

Fonte: Elaborado pelos autores. 
No sentido de afastar os fatores que geram a desmobilização, as lideranças comunitárias esforçam-se para buscar apoio e novos parceiros, na tentativa de combater a negação e o silenciamento em torno da causa, dar visibilidade ampla à situação das periferias, além de aumentar o volume de doações. E esse esforço de convencimento não se limita à sociedade civil: as lideranças reivindicam o apoio do Estado nesse movimento. Com efeito, a ausência do poder público é mencionada por quase todos os grupos que participaram da dinâmica.

Ao passo que as lideranças somam esforços para gerar vínculos com a sociedade e constituir redes mais fortes, suficientes para sobrepujar os constrangimentos como insegurança, incerteza, medo e dúvidas que pontuam o processo de solidariedade, e que demanda a todo momento o convencimento do outro não só para manter o grupo mobilizado como para seguir as regras básicas de prevenção ao contágio de Covid-19.

O que se percebe é também uma falta de comunicação confiável acerca de situação da pandemia na própria periferia, o que dificulta a criação desses vínculos, tão necessários em momentos emergenciais, especialmente de segurança alimentar e proteção. "Como atuar nesse novo contexto?", indaga um participante do Grupo 1, diante das dúvidas e incertezas no tocante ao enfrentamento da pandemia nas condições atuais. Nesse cenário, é preciso repensar as estratégias e os modos de ação: "Saber pedir: o que pedir, pra quem pedir, como pedir”, assegura um participante do Grupo 1.

c) Condições de empatia - A falta de empatia com as populações vulneráveis, que parece dificultar a interação entre a periferia e o centro, amplia uma histórica separação desses espaços. 0 isolamento e o déficit no acesso à tecnologia tornam ainda mais distante o desejo de sensibilizar quem não está nas periferias. No Quadro 3, elencamos algumas falas dos participantes que dizem um pouco sobre essa ausência. 
Quadro 3. Proferimentos sobre as condições de empatia

\begin{tabular}{|l|}
\hline \multicolumn{2}{|c|}{ Condições de empatia - Proferimentos ressaltados } \\
\hline $\begin{array}{l}\text { “Como quebrar a barreira da invisibilidade, ocupar os espaços e lutar?” } \\
\text { (Participante do Grupo 1) }\end{array}$ \\
\hline “Precisamos 'megafonizar' a nossa voz, para que os coletivos em que atuamos \\
possam furar a bolha e falar com a sociedade. Eu acho que esse é o grande desafio \\
do Periferia Viva como um todo também, hoje e no futuro”. (Participante do Grupo \\
1) \\
\hline “A comunicação é vista aqui como uma potência tanto na escuta quanto na fala e \\
precisamos nos organizar em rede e promover trocas que nos fortaleçam”. \\
(Participante do Grupo 7)
\end{tabular}

Fonte: Elaborado pelos autores.

A dificuldade de aproximação é notória frente a mudança dos meios de contato. 0 preconceito, que vem da divisão social, se acentua, aumentam o distanciamento e as barreiras do isolamento até mesmo no acesso ao Estado e seus serviços, impedindo o favorecer coletivo. E sensibilizar a sociedade parece ser um dos principais objetivos das comunidades periféricas, como observaram os líderes comunitários no encontro do projeto. E tal aproximação tem uma razão imediata: a necessidade de obter mais doações, pois é grande a "angústia por não conseguir atender a todas as demandas", registram os líderes comunitários.

Nesse sentido, "sensibilizar a sociedade" parece ser uma necessidade entre os grupos que participaram do encontro da rede PV. Como os próprios voluntários enumeram, é preciso, em caráter emergencial, “conseguir voluntários especializados (saúde, assistência social, educação)" e "doações regulares"; é preciso "extrapolar a bolha" para conseguir recursos; e "obter ajuda popular”, porque o desamparo é grande e compete com os esforços do grupo de voluntários para levar ajuda a quem precisa.

Para reduzir o déficit de empatia, é preciso, ainda, segundo as lideranças, avançar nas questões estratégicas, tendo conhecimento profundo da área em que atuam, e ampliar a comunicação externa com ações que se traduzam em parcerias mais efetivas e próximas 
à causa, como a universidade pública, como forma de fazer frente ao preconceito que restringe as possibilidades de aproximação.

\section{Considerações finais}

Há constantes disputas ao redor da formação e movimentação de um público. Forças multidirecionais tensionam esse processo a todo momento, tornando-o dinâmico, gerando menos ou mais engajamento, agindo menos ou mais contrariamente. Ao mesmo tempo que atores que se entendem como afetados buscam mobilizar outros sujeitos, forças diversas criam resistências e entraves para esse processo. Nesse cenário, é preciso ressaltar que falar/pensar em desmobilização não significa negar a ideia de mobilização. Pelo contrário, são um só processo.

Nossa abordagem neste texto se concentrou em entender como as dinâmicas de (des)mobilização implicam interações e vetores de força que entram em jogo e configuram tanto a constituição dos públicos quanto suas possibilidades de atuação na sociedade contemporânea. A literatura nos mostrou que fatores como a disposição, a introspecção, os atos de ignorar, negar e ou não dar atenção incidem sobre a mobilização, gerando obstáculos ao seu processo.

Do ponto de vista empírico, para termos uma visão panorâmica da situação das periferias, analisamos especificamente o $1 .^{\circ}$ Encontro do Periferia Viva, que reuniu mais de 50 pessoas em torno da discussão de quatro questões principais, relacionadas aos desafios encontrados, os aprendizados, as tendências futuras e as possibilidades de atuação em rede. Com isso pudemos evidenciar, para além dos fatores contextuais, alguns fatores comunicacionais importantes. Sobre os fatores comunicacionais, identificamos que o isolamento e a falta de empatia têm grande impacto no processo de coletivização das causas/pautas dos grupos atuantes nas periferias. 0 isolamento modificou profundamente as formas comuns de sociabilidade, alterou os vínculos comunitários, impondo limitações físicas e simbólicas entre as pessoas. Já a questão da empatia se evidencia na dificuldade que os grupos têm de transcender os muros que separam "periferia" e "centro", de falar para grupos externos às periferias, de amplificar suas falas. Além disso, as condições de coletivização são prejudicadas pela própria dificuldade no entendimento do problema, em ambiente controverso e de várias incertezas. Nosso ponto de observação tem a ver com alguns fatores que causam, portanto, uma força contrária à da mobilização. Para os grupos 
já mobilizados, isso implica em mais esforço para se contrapor a estes fatores. Para a ampliação da mobilização, isso é um obstáculo para a adesão e ação de um contingente maior de pessoas e grupos, num ambiente social mais amplo.

Ao destacarmos e analisarmos os fatores de desmobilização não queremos, de modo algum, menosprezar todo o esforço realizado por diversos públicos. Queremos, com isso, demonstrar a tensão entre estes fatores e ressaltar as estratégias que impulsionam as atitudes e ações efetivas. Assim, no caso que examinamos, há relatos muito significativos sobre essas estratégias. No que tange à visibilidade, observa-se não somente a denúncia das condições dessa população, mas um viés afirmativo importante, que valoriza a realidade comunitária como algo fundamental para o enfrentamento à epidemia.

O que se viu, afinal, no $1 .^{\circ}$ Encontro do Periferia Viva, foi uma rede heterogênea, ou seja, uma periferia viva, apesar de traços e condições comuns bastante diversos. Também são os demais atores que se juntam à mobilização, na perspectiva de uma dinâmica aberta e incerta dos públicos. Por fim, cabe também ressaltar a visão de futuro que esses coletivos apresentaram, não apenas sobre o fortalecimento dessa rede, inserida e atravessada por outras redes mais, como também para a formação do comum no cenário já transformado pela pandemia. Estas esperanças são traduzidas, por exemplo, pelo desejo em se explorar as possibilidades do mundo digital e ampliar seus espectros de atuação, tecer novas redes e levar as causas das periferias para mais pessoas.

\section{Referências}

DEWEY, J. The public and its problems. Ohio: Swallow Press Books, 1954.

ESTEVES, J. P. Sociologia da comunicação. Lisboa: Fundação Calouste Gulbenkian, 2011.

HENRIQUES, M. S. Comunicação e mobilização social na prática da polícia comunitária. Belo Horizonte: Editora Autêntica, 2010.

HENRIQUES, M. S. A comunicação e a condição pública dos processos de mobilização social. Revista Ação Midiática - Estudos em Comunicação, Sociedade e Cultura, UFPR, PPGCOM, v.2. n.1, p.1-12, 2012.

HENRIQUES, M. S. Dimensões dos públicos nos processos de comunicação pública: formas de conhecimento, ação e organização. In: SCROFERNEKER, C. M. A.; AMORIM, L. R. (Orgs.) (Re) leituras contemporâneas sobre comunicação organizacional e relações públicas. Porto Alegre: EDIPUCRS, 2017. 
HENRIQUES, M. S.; BRAGA, C. S.; SILVA, D. B. C.; MAFRA, R. L. M. Relações Públicas em Projetos de Mobilização Social: funções e características. In: HENRIQUES, Márcio Simeone (Org.). Comunicação e Estratégias de Mobilização Social. 3. ed. Belo Horizonte: Autêntica, 2013.

KRZNARIC, R. 0 poder da empatia: a arte de se colocar no lugar do outro para transformar o mundo. Tradução Maria Luiza X. de A. Borges. 1.ed. Rio de Janeiro: Zahar, 2015.

OSUBH. $4^{\circ}$ InfoCovid. Disponível em: https://www.medicina.ufmg.br/coronavirus/wpcontent/uploads/sites/91/2020/07/InfoCOVID-04_16-jul_atuzalizado.pdf. Acesso em: 30 jul. 2020

PIMENTA, L. Processos mobilizadores em contextos embaraçosos: a atuação dos agentes implementadores no enfrentamento à exploração sexual infantojuvenil no Vale do Jequitinhonha. 2019. 295f. Tese, UFMG, MG.

SILVA, D. R. Dinâmicas da desmobilização: a criação de entraves aos processos de formação e movimentação de públicos. Anais do XXVIII Encontro Anual da Compós, PUCRS, Porto Alegre - RS, 11 a 14 de junho de 2019

TORO, J. B.; WERNECK, N. M. D. Mobilização social: um modo de construir a democracia e a participação. Belo Horizonte: Autêntica, 2004.

ZERUBAVEL, E. Hidden in plain sight: the social structure of irrelevance. New York: Oxford University Press, 2015.

ZERUBAVEL, E. The elephant in the room: silence and denial in everyday life. New York: Oxford University Press, 2006. 
Como citar este artigo

PIMENTA, Laura Nayara; HENRIQUES, Márcio Simeone; MACHADO, Marlene Pereira. Fatores de (des)mobilização social no enfrentamento à pandemia de Covid-19 pelas populações periféricas de Belo Horizonte, Minas Gerais. Revista Dispositiva. [on-line] Disponível em: <http://periodicos.pucminas.br/index.php/dispositi va> Dossiê: Comunicação, política e saúde. Editoras Responsáveis: Fernanda Sanglard e Vanessa Veiga de Oliveira. Volume 9, Número 16, Belo Horizonte, dezembro de 2020, p. 87-106. Acesso em "dia/mês/ano".

Texto recebido em: $24 / 08 / 2020$

Texto aprovado em: 16/11/2020 